\title{
Quantity Discount Supply Chain Models with Fashion Products and Uncertain Yields
}

\author{
Hongjun Peng and Meihua Zhou \\ School of Management, China University of Mining and Technology, Xuzhou, Jiangsu 221116, China \\ Correspondence should be addressed to Meihua Zhou; mhzhou63@126.com
}

Received 11 October 2012; Revised 3 December 2012; Accepted 7 December 2012

Academic Editor: Tsan-Ming Choi

Copyright ( 2013 H. Peng and M. Zhou. This is an open access article distributed under the Creative Commons Attribution License, which permits unrestricted use, distribution, and reproduction in any medium, provided the original work is properly cited.

\begin{abstract}
This paper explores the quantity discount coordination models in the fashion supply chain with uncertain yields and random demand. The paper proves that, under the independent and noncoordinated decision patterns, there exists a Nash equilibrium between the supplier and the manufacturer which reduces the supply chain's profit margin. In order to achieve the "optimal" centralized supply chain expected profit margin, new quantity discount models have been established. Both the supplier-oriented and the manufacturer-oriented Stackelberg supply chain gaming models are investigated. Our analytical and numerical analyses show that the quantity discount contract proposed in this paper can largely reduce the negative influence brought by the uncertainty of yields and demand. Therefore, the profit margin of supply chains based on quantity discount can reach the optimal level of the supply chain under the centralized setting.
\end{abstract}

\section{Introduction}

Supply chain coordination has been the central theme for the majority of supply chain management researches. Efforts have been made in the development of coordination mechanisms, aiming to allow a decentralized supply chain to perform as effectively as a centralized one by aligning chain members' objectives with a chain-wide objective [1]. Efforts have also been made in exploring sourcing strategies in a decentralized supply chain, as multiple sourcing is not uncommon in various industrial sectors [2-5] and in analyzing the dynamics of interaction among chain members [6-8].

This paper adds to these growing efforts of improving supply chain effectiveness by analyzing the quantity discount contract in a fashion supply chain characterized by the uncertainty in two-echelon yields and random demand, namely, the uncertainty in the production of raw materials and in the production of finished goods (as Figure 1).

The coordination of a supply chain with the manufacturer output uncertain, especially with uncertainity in two-echelon yields and demand has not researched. The optimal planned production and the ordering quantity have a close bearing on the uncertainty in two-echelon yields and demand [9].
It is of important significance to research the coordination mechanism of supply chain with uncertainity in two-echelon yields and demand. This paper mainly researches the quantity discount contract and model in the fashion supply chain with uncertainty in two-echelon yields and demand. It analyses how to determine the qualification point of quantity discount and the discount rate so as to reach the profit level of the supply chains based on centralized decision making.

\section{Literature Review}

Quantity discounts have received significant attention in the literatures, and numerous inventory models have considered quantity discounts [10-14]. Some literatures showed that the application of all-unit discounts contributes to reducing the buyer's inventory cost and improving the supplier's profit simultaneously [15-20]. A mixed integer programming approach was presented for solving the multiperiod inventory problem with price quantity discount [17, 20-23]. Rezaei and Davoodi [24] considered inventory lot sizing and imperfect items in a supply chain and proposed a MIP for supplier selection under an environment with multiple suppliers and multiple products with quantity discounts. Duan et al. 


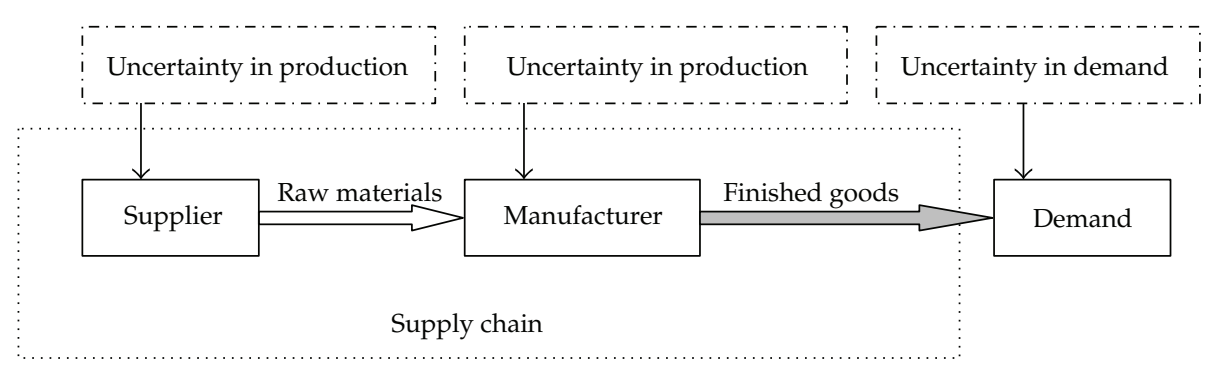

FIGURE 1: Supply chain with uncertainty in two-echelon yields and demand.

[25] considered a single-vendor, single-buyer supply chain for a fixed lifetime product and proposed decision making models to analyze the benefit of coordinating the supply chain through a quantity discount strategy. Munson and $\mathrm{Hu}$ [14] presented methodologies to calculate the optimal order quantities and computed the total purchasing and the inventory costs when products have either all-unit or incremental quantity discounts. Chen and Ho [26] presented an analysis method for the single-period inventory problem with fuzzy demands and incremental quantity discounts, with the objective of minimizing the total cost per unit time. Lin and Ho [27] aimed to find the optimal pricing and ordering strategies for an integrated inventory system when a quantity discount policy is present and the market demand is price sensitive. Krichen et al. [28] constructed a single supplier, multiple cooperative retailers inventory model with quantity discount and permissible delay in payments. A decision rule that helps each retailer to enumerate the preferred coalitions was proposed, and an algorithm that generated coalition structures in the core was presented. Shi et al. [29] aimed to maximize the expected profit of the retailer through jointly determining the ordering quantities and selling prices for the products with the consideration of all-units quantity discounts and newsvendor pricing. The problem was formulated as a generalized disjunctive programming model, and a Lagrangian heuristic approach was developed. Taleizadeh et al. [23] studied a multiproduct, multiconstraint joint-replenishment inventory control problem in which an incremental discount policy was used and transportation, clearance, fixed order, holding, and shortage costs were considered.

Almost all the papers researched the quantity discount contract in the assumption that the supplier was in the dominant position. In fact, to a supply chain made up of suppliers and manufacturers, the manufacturers may predominate in the negotiations of quantity discount by deciding the qualification point and price discount rate. Secondly, most quantity discount models consider deterministic yields and demand, assuming that the buyer faces no risk when accepting quantity discounts from the supplier [30].

Uncertainty on the supply side was researched by several papers [31-42]. Tomlin [41], for instance, studied a firm's disruption-management strategy in a dual-sourcing setting in which its two independent suppliers have heterogeneous capacities, reliabilities, flexibilities, and cost structures. Hsieh and $\mathrm{Wu}[35]$ studied coordination mechanisms in a supply chain which consists of two suppliers with capacity uncertainties selling differential yet substitutable products through a common retailer who faces price-sensitive random demand of these two products. Keren [38] explored a special form of the single-period inventory problem (newsvendor problem) with a known demand and stochastic supply (yield) in the supply chain with a supplier and a distributor. He and Zhang $[32,33]$ studied a simple supply chain with one supplier and one retailer where there was random-yield production and uncertain demand. Yan et al. [40] studied the coordination of a decentralized assembly system in which the demand of the assembler is deterministic and the component yields are random. Kelle et al. [37] focused on the inventory-related costs that can be influenced by adjusting the ordering, setup, and delivery policy to the random yield. The yield model of having a random proportion of defective items is assumed with known mean and variance.

The papers above mainly touched upon the issue of optimized operation and coordination under one supplier and one distributor. In the supply chain, the supply bears uncertainty. The papers above did not research the operation or coordination of supply chain with the manufacturer output uncertain, especially with uncertain two-echelon yields and demand. To deal with the decision-making problems of producing and ordering in the supply chain which are characterized by the uncertainty two-echelon yields and random demand, Peng and Zhou [9] established inventory models of supply chains including both centralized and decentralized decision making. The study showed that the optimal planned production and ordering quantity have a close bearing on the risks in two-echelon yields and demand. It is thus worthwhile to further research the coordination mechanism and the model of supply chain with uncertainity in two-echelon yields and demand.

This paper mainly deals with the quantity discount contract in a fashion supply chain when two-echelon yields and demand are nondetermined at the same time. A model of quantity discount coordination has been established accordingly, intended to figure out the optimal planned production by the supplier and the optimal ordering quantity by the manufacturer under the quantity discount contract. It also analyses how to determine the qualification point of quantity discount and the discount rate so as to reach the same profit margin as the centralized decision making.

This paper contributes to the current literature in the following aspects. 
Firstly, available literatures mainly cover supply chains consisting of suppliers and distributors, with the production from the former bearing uncertainty. This paper deals with a supply chain consisting of one supplier and one manufacturer, among which the production of two-echelon yields and the demand of the products bear uncertainty. Finished goods are produced after the manufacturer has ordered the raw materials, and the uncertainty appears in the process of production. In supply chains as such, the supplier and the manufacturer are faced up with a more complex and uncertain environment in operation and decision making, with its operational processes and coordination mechanisms largely differentiated from supply chains consisting of one supplier and one distributor.

Secondly, a quantity discount model has been established and two sets of the Stackelberg game of quantity discount have been put forward on the basis of a supplier-oriented pattern and a manufacturer-oriented pattern, respectively.

Thirdly, the result shows that quantity discount contract proposed by this paper can largely reduce the negative influence imposed by the uncertainty of two-echelon yields and demand upon the market benefits of the supply chains. Therefore, the profit margin of supply chains based on quantity discount can reach the profit level of the supply chains based on centralized decision making.

\section{Presumptions and Markings of Model}

In the analysis, the major presumptions are as follows.

(1) The research design is based on a two-level fashion supply chain system consisting of a single supplier and a single manufacturer. The supplier produces the raw material which is to be sold to the manufacturer and the latter then produces the finished products.

(2) There exist uncertainty and independent attribute in all the three elements - the output of the supplier, the output of the manufacturer, and the market demand of the finished products. In the meanwhile, the precondition is set that the expected mean value of the actual output by the supplier and the manufacturer amounts to the planned output.

(3) JIT is adopted as the mode of supply and the delivery quantity by the supplier does not exceed the ordering quantity by the manufacturer.

(4) The output ratio from the raw material to the finished products is $1: 1$, specifically, one unit of finished products requires one unit of raw material. If the output ratio is not as designed, it can be realized through adaptation of the model. Therefore, the ratio hypothesized would not affect the result of the experiment.

(5) The supplier and the manufacturer would have to operate abiding by the Stackelberg game. This paper, respectively, analyzes the quantity discount contracts on the condition either when the supplier is set as the dominant side or when the manufacturer is set as the dominant side.
TABLE 1: Instruction for variables.

\begin{tabular}{ll}
\hline Variable & Definition \\
\hline$h_{0}$ & Inventory cost for raw material per unit \\
$h_{1}$ & Inventory cost for finished products per \\
$r_{0}$ & unit \\
$r_{1}$ & Shortage cost for raw material per unit \\
$c_{0}$ & Shortage cost for finished product per unit \\
$c_{1}$ & Cost of production of raw material per unit \\
$p_{0}$ & Cost of production of finished product per \\
$p_{1}$ & unit \\
$\pi_{0}$ & Price of the raw material per unit \\
$\pi_{1}$ & Price of finished product per unit \\
$\pi_{2}$ & Total profit of the supply chain \\
$q_{0}$ & Profit for the supplier \\
$q_{1}$ & Profit for the manufacturer \\
$X$ & Planned output of the supplier \\
$Y$ & Ordering quantity by the manufacturer \\
$Z$ & Random variables by the supplier \\
$D$ & Random variable by the manufacturer \\
$f_{1}(x)$ & Random variables of market demand \\
$f_{2}(y)$ & Expectation of the market demand \\
$g(z)$ & Probability density function of $X$ \\
$q^{*}$ & Probability density function of $Y$ \\
$\alpha$ & Probability density function of $Z$ \\
$U$ & Qualification point of quantity discount \\
$C$ & Discount rate of the price \\
\hline & decision \\
\hline Centralized decision \\
\end{tabular}

Major variables are shown in Table 1.

\section{Analysis of the Necessity of the Coordination of the Supply Chain When Two-Echelon Yields and Demand Are Uncertain}

4.1. Production and Ordering Decision Making by an Independent and Noncoordinated Decision-Making Pattern. When the supplier and the manufacturer work in an independent and noncoordinated fashion, the decision for output and ordering is made by the standard of maximizing their profits. The manufacturer first orders a certain amount of raw material, $q_{1}$, from the supplier, and then the latter prepares the production quantity, $q_{0}$.

Two-echelon yields and demand in the supply chain are uncertain at the same time. Suppose that the actual output is $q_{0} X$; according to hypothesis (3), the amount of raw material received by the manufacturer is no more than the ordering quantity, so the final production output is $\min \left(q_{1}, q_{0} \cdot X\right) \cdot Y$. The market demand of the finished products is $D \cdot Z$, then 
the expected value of $Z$ is 1 . According to hypothesis (2), the expected values of $X, Y$ are 1 .

Under the independent and noncoordinated decisionmaking pattern, the profit gained by the supplier is

$$
\begin{aligned}
\pi_{1}^{U}\left(q_{0}\right)= & p_{0} \min \left[q_{1}, q_{0} \cdot X\right]-c_{0} q_{0}-h_{0} \max \left[q_{0} \cdot X-q_{1}, 0\right] \\
& -r_{0} \max \left[q_{1}-q_{0} \cdot X, 0\right] .
\end{aligned}
$$

The first term is its sales revenue, the second term is the production cost of the supplier, the third term is the inventory cost of the raw material by the supplier, and the fourth term is the shortage cost of the raw material. The expected profit by the supplier is

$$
\begin{aligned}
E\left[\pi_{1}^{U}\left(q_{0}\right)\right]= & p_{0}\left[\int_{0}^{q_{1} / q_{0}}\left(q_{0} \cdot x\right) f_{1}(x) d x\right. \\
& \left.\quad+\int_{q_{1} / q_{0}}^{+\infty} q_{1} f_{1}(x) d x\right] \\
& -c_{0} q_{0}-h_{0} \int_{q_{1} / q_{0}}^{+\infty}\left(q_{0} \cdot x-q_{1}\right) f_{1}(x) d x \\
& -r_{0} \int_{0}^{q_{1} / q_{0}}\left(q_{1}-q_{0} \cdot x\right) f_{1}(x) d x .
\end{aligned}
$$

Proposition 1. (1) Under the independent and noncoordinated decision-making pattern, the expected profit by the supplier, $E\left(\pi_{1}^{U}\right)$, is concave in $q_{0}$, and the optimal planned output of the raw material, $q_{0}^{U}$, conforms to the following formula:

$$
\int_{0}^{q_{1} / q_{0}^{U}} x f_{1}(x) d x=\frac{c_{0}+h_{0}}{p_{0}+h_{0}+r_{0}}=1-\frac{p_{0}+r_{0}-c_{0}}{p_{0}+h_{0}+r_{0}},
$$
$f_{1}(\cdot)$.

(2) $q_{0}^{U}=\lambda q_{1}$, where $\lambda$ is determined by $p_{0}, h_{0}, r_{0}, c_{0}$, and

Proof. (1)

$$
\begin{gathered}
\frac{d E\left[\pi_{1}^{U}\left(q_{0}\right)\right]}{d q_{0}}=\left(p_{0}+h_{0}+r_{0}\right) \int_{0}^{q_{1} / q_{0}} x f_{1}(x) d x-c_{0}-h_{0}, \\
\frac{d^{2} E\left[\pi_{1}^{U}\left(q_{0}\right)\right]}{d q_{0}^{2}}=-\left(p_{0}+h_{0}+r_{0}\right) \frac{q_{1}^{2}}{q_{0}^{3}} f_{1}\left(\frac{q_{1}}{q_{0}}\right)<0 .
\end{gathered}
$$

So $E\left(\pi_{1}^{U}\right)$ is concave in $q_{0}$, and setting $\left(d E\left(\pi_{1}^{U}\right)\right) / d q_{0}=0$, we can derive (3).

(2) All we need to show is that function $T_{1}(u)=$ $\int_{0}^{u} x f(x) d x$ is a monotone function of $u$, which is obvious from $d T_{1} / d u=u f(u)>0$. Therefore, (2) has a unique solution, and $q_{1} / q_{0}$ is denoted as $1 / \lambda$ here.
Under the independent and noncoordinated decision making pattern, the expected profits by the manufacturer are

$$
\begin{aligned}
\pi_{2}^{U}\left(q_{1}\right)= & p_{1} \min \left[D \cdot Z, k \cdot \min \left(q_{1}, q_{0} \cdot X\right) \cdot Y\right] \\
& -p_{0} \min \left[q_{1}, q_{0} \cdot X\right]-c_{1} \min \left(q_{1}, q_{0} \cdot X\right) \\
& -h_{1} \max \left[\min \left(q_{1}, q_{0} \cdot X\right) \cdot Y-D \cdot Z, 0\right] \\
& -r_{1} \max \left[D \cdot Z-\min \left(q_{1}, q_{0} \cdot X\right) \cdot Y, 0\right]
\end{aligned}
$$

The first term is the manufacturer's sales revenue, the second term is the ordering cost for the raw material, the third term is the production cost, the fourth term is the inventory cost, and the fifth term is the shortage cost.

The manufacturer finds out the optimal order quantity where the supplier's problem of finding the optimal production quantity is a constraint in the mathematical programming problem:

$$
\begin{aligned}
& \max _{q_{1}} E\left[\pi_{2}^{U}\left(q_{1}\right)\right] \\
& =p_{1} \int_{0}^{+\infty} g(z) d z \\
& \times\left[\int_{0}^{q_{1} / q_{0}} d x \int_{0}^{D z / q_{0} x} q_{0} x y f_{1}(x) f_{2}(y) d y\right. \\
& +\int_{0}^{q_{1} / q_{0}} d x \int_{D z / q_{0} x}^{+\infty} D z f_{1}(x) f_{2}(y) d y \\
& +\int_{q_{1} / q_{0}}^{+\infty} d x \int_{0}^{D z / q_{1}} q_{1} y f_{1}(x) f_{2}(y) d y \\
& \left.+\int_{q_{1} / q_{0}}^{+\infty} d x \int_{D z / q_{1}}^{+\infty} D z f_{1}(x) f_{2}(y) d y\right] \\
& -\left(p_{0}+c_{1}\right)\left[\int_{0}^{q_{1} / q_{0}} q_{0} x f_{1}(x) d x\right. \\
& \left.+\int_{q_{1} / q_{0}}^{+\infty} q_{1} f_{1}(x) d x\right] \\
& -h_{1} \int_{0}^{+\infty} g(z) d z \\
& \times\left[\int_{0}^{q_{1} / q_{0}} d x\right. \\
& \times \int_{D z / q_{0} x}^{+\infty}\left(q_{0} x y-D z\right) f_{1}(x) f_{2}(y) d y \\
& +\int_{q_{1} / q_{0}}^{+\infty} d x \\
& \left.\times \int_{D z / q_{1}}^{+\infty}\left(q_{1} y-D z\right) f_{1}(x) f_{2}(y) d y\right]
\end{aligned}
$$




$$
\begin{aligned}
& -r_{1} \int_{0}^{+\infty} g(z) d z \\
& \times\left[\int_{0}^{q_{1} / q_{0}} d x\right. \\
& \quad \times \int_{0}^{D z / q_{0} x}\left(D z-q_{0} x y\right) f_{1}(x) f_{2}(y) d y \\
& \quad+\int_{q_{1} / q_{0}}^{+\infty} d x \\
& \left.\quad \times \int_{0}^{D z / q_{1}}\left(D z-q_{1} y\right) f_{1}(x) f_{2}(y) d y\right]
\end{aligned}
$$

s.t. $\quad q_{0}^{U}=\lambda q_{1}$.

Proposition 2. Under the independent and noncoordinated decision-making pattern, the manufacturer's expected profit function, $E\left(\pi_{1}^{U}\right)$, is concave in $q_{1}$, and the optimal order quantity, $q_{1}^{U}$, satisfies the following equation:

$$
\begin{gathered}
\int_{0}^{+\infty} g(z) d z\left[\int_{0}^{1 / \lambda} d x \int_{0}^{D z / \lambda q_{1}^{U} x} \lambda x y f_{1}(x) f_{2}(y) d y\right. \\
\left.+\int_{1 / \lambda}^{+\infty} d x \int_{0}^{D z / q_{1}^{U}} y f_{1}(x) f_{2}(y) d y\right] \\
=\frac{\left(p_{0}+c_{1}+h_{1}\right)\left[\int_{0}^{1 / \lambda} \lambda x f_{1}(x) d x+\int_{1 / \lambda}^{+\infty} f_{1}(x) d x\right]}{p_{1}+r_{1}+h_{1}} .
\end{gathered}
$$

Proof. Since $q_{0}^{U}\left(q_{1}\right)=\lambda q_{1}$,

$$
\begin{aligned}
\frac{d E\left[\pi_{2}\right]}{d q_{1}}= & \left(p_{1}+r_{1}+h_{1}\right) \int_{0}^{+\infty} g(z) d z \\
& \times\left[\int_{0}^{1 / \lambda} d x \int_{0}^{D z / \lambda q_{1} x} \lambda x y f_{1}(x) f_{2}(y) d y\right. \\
& \left.\quad+\int_{1 / \lambda}^{+\infty} d x \int_{0}^{D z / q_{1}} y f_{1}(x) f_{2}(y) d y\right] \\
& -\lambda\left(p_{0}+c_{1}+h_{1}\right) \\
& +\left(p_{0}+c_{1}\right) \int_{1 / \lambda}^{+\infty}(\lambda x-1) f_{1}(x) d x,
\end{aligned}
$$

$$
\frac{d^{2} E\left[\pi_{2}\right]}{d q_{1}^{2}}=-\left(p_{1}+h_{1}+r_{1}\right) \int_{0}^{+\infty} g(z) d z
$$

$$
\begin{aligned}
& \times\left[\int_{0}^{1 / \lambda} \frac{(D z)^{2}}{\lambda q_{1}^{3} x} f_{1}(x) f_{2}\left(\frac{D z}{\lambda q_{1} x}\right) d x\right. \\
& \left.\quad+\int_{1 / \lambda}^{+\infty} \frac{(D z)^{2}}{q_{1}^{3}} f_{1}(x) f_{2}\left(\frac{D z}{q_{1}}\right) d x\right]<0 .
\end{aligned}
$$

So $E\left(\pi_{2}^{U}\right)$ is concave in $q_{1}$, and setting $\left(d E\left(\pi_{2}^{U}\right)\right) / d q_{1}=0$, we have (7).

4.2. Production and Ordering Decision Making Guided by a Centralized Decision-Making Pattern. In the centralized supply chain, the goal of the supply chain operation is to maximize the total profit. The manufacturer directly conveys the demand information to the supplier. In the centralized case, the shortage cost of the supplier can be seen as a matter of an internal revenue transfer, which barely affects the decision making in production and ordering. The profit generated by the supply chain dependent on the centralized decision making is

$$
\begin{aligned}
\pi_{0}^{C}= & p_{1} \min \left[D \cdot Z, \min \left(q_{1}, q_{0} \cdot X\right) \cdot Y\right] \\
& -c_{1} \min \left(q_{1}, q_{0} \cdot X\right)-c_{0} q_{0}-h_{0} \max \left[q_{0} \cdot X-q_{1}, 0\right] \\
& -h_{1} \max \left[\min \left(q_{1}, q_{0} \cdot X\right) \cdot Y-D \cdot Z, 0\right] \\
& -r_{1} \max \left[D \cdot Z-\min \left(q_{1}, q_{0} \cdot X\right) \cdot Y, 0\right] .
\end{aligned}
$$

The operational goal is to realize the maximized profit in this supply chain, and the operational model is

$$
\begin{aligned}
& \max E\left[\pi_{0}^{C}\right] \\
&= p_{1} \int_{0}^{+\infty} g(z) d z \\
& \times\left[\int_{0}^{q_{1} / q_{0}} d x \int_{0}^{D z / q_{0} x} q_{0} x y f_{1}(x) f_{2}(y) d y\right. \\
& \quad+\int_{0}^{q_{1} / q_{0}} d x \int_{D z / q_{0} x}^{+\infty} D z f_{1}(x) f_{2}(y) d y \\
& \quad+\int_{q_{1} / q_{0}}^{+\infty} d x \int_{0}^{D z / q_{1}} q_{1} y f_{1}(x) f_{2}(y) d y \\
&\left.\quad+\int_{q_{1} / q_{0}}^{+\infty} d x \int_{D z / q_{1}}^{+\infty} D z f_{1}(x) f_{2}(y) d y\right] \\
&-c_{0} q_{0}-h_{0} \int_{q_{1} / q_{0}}^{+\infty}\left(q_{0} \cdot x-q_{1}\right) f_{1}(x) d x
\end{aligned}
$$




$$
\begin{aligned}
& -c_{1}\left[\int_{0}^{q_{1} / q_{0}} q_{0} x f_{1}(x) d x+\int_{q_{1} / q_{0}}^{+\infty} q_{1} f_{1}(x) d x\right] \\
& -h_{1} \int_{0}^{+\infty} g(z) d z \\
& \times\left[\int_{0}^{q_{1} / q_{0}} d x \int_{D z / q_{0} x}^{+\infty}\left(q_{0} x y-D z\right) f_{1}(x) f_{2}(y) d y\right. \\
& \left.\quad+\int_{q_{1} / q_{0}}^{+\infty} d x \int_{D z / q_{1}}^{+\infty}\left(q_{1} y-D z\right) f_{1}(x) f_{2}(y) d y\right] \\
& -r_{1} \int_{0}^{+\infty} g(z) d z \\
& \times\left[\int_{0}^{q_{1} / q_{0}} d x \int_{0}^{D z / q_{0} x}\left(D z-q_{0} x y\right) f_{1}(x) f_{2}(y) d y\right. \\
& \left.\quad+\int_{q_{1} / q_{0}}^{+\infty} d x \int_{0}^{D z / q_{1}}\left(D z-q_{1} y\right) f_{1}(x) f_{2}(y) d y\right] .
\end{aligned}
$$

Proposition 3. Consider $E\left[\pi_{0}^{C}\right] \geq E\left[\pi_{1}^{U}\right]+E\left[\pi_{2}^{U}\right]$.

Proof. From (1), (5), and (10), we can obtain

$$
\begin{aligned}
E\left[\pi_{0}^{C}\right] & \geq E\left[\pi_{1}\left(q_{0}^{C}\right)\right]+E\left[\pi_{2}\left(q_{1}^{C}\right)\right]=\max _{q_{0}, q_{1}} E\left[\pi_{0}\left(q_{0}, q_{1}\right)\right] \\
& \geq E\left[\pi_{1}\left(q_{0}^{U}\right)\right]+E\left[\pi_{2}\left(q_{1}^{U}\right)\right]=E\left[\pi_{1}^{U}\right]+E\left[\pi_{2}^{U}\right] .
\end{aligned}
$$

Proposition 3 illustrates that, under the independent and noncoordinated decision making pattern, the Nash equilibrium existing between the supplier and the manufacturer reduces the profit of the supply chain. In order to fulfill the profit margin in the centralized supply chains under the independent decision-making pattern, there is a necessity to design an efficient coordinating mechanism.

\section{Production and Ordering Decision under Quantity Discount Coordination}

According to (7), the ordering quantity by the manufacturer decreases with the price of the raw material. In this sense, a quantity discount contract amounts to the reduction of the ordering price of the raw material, through which the ordering quantity by the manufacturer can be promoted. The study is based on the quantity discount contract, conforming to which qualification point of quantity discount, $q^{*}$, and price discount rate, $\alpha$, can be established. When the amount of the raw material provided by the supplier to the manufacturer is less than $q^{*}$, the price is set at $p_{0}$; when the amount of the raw material exceeds $q^{*}$, the price of the excess part is set at $(1-\alpha) p_{1}$, where $0<\alpha<1$.
Under the quantity discount contract, the profit of the supplier is given as follows:

$$
\begin{aligned}
\pi_{1}^{\mathrm{QD}}\left(q_{0}\right)= & p_{0} \min \left[q_{1}, q_{0} X\right] \\
& -\alpha p_{0} \max \left[\min \left(q_{1}, q_{0} X\right)-q^{*}, 0\right] \\
& -c_{0} q_{0}-h_{0} \max \left[q_{0} X-q_{1}, 0\right] \\
& -r_{0} \max \left[q_{1}-q_{0} X, 0\right] .
\end{aligned}
$$

The first term is the sales revenue of the supplier at the price of $p_{0}$, the second term is the price discount given to manufacturer on the basis of quantity discount, the third term is the production cost of the supplier, the fourth term is the inventory cost of the supplier, and the fifth term is the shortage cost of the raw material, and the sixth term is the shortage cost of the raw material.

Under the quantity discount contract, the expected profit of the supplier is

$$
\begin{aligned}
& E\left[\pi_{1}^{\mathrm{QD}}\left(q_{0}\right)\right] \\
& =p_{0}\left[\int_{0}^{q_{1} / q_{0}}\left(q_{0} x\right) f_{1}(x) d x+\int_{q_{1} / q_{0}}^{+\infty} q_{1} f_{1}(x) d x\right]-\alpha p_{0} \\
& \quad \times\left[\int_{q^{*} / q_{0}}^{q_{1} / q_{0}}\left(q_{0} x-q^{*}\right) f_{1}(x) d x\right. \\
& \left.\quad+\int_{q_{1} / q_{0}}^{+\infty}\left(q_{1}-q^{*}\right) f_{1}(x) d x\right] \\
& \quad-c_{0} q_{0}-h_{0} \int_{q_{1} / q_{0}}^{+\infty}\left(q_{0} x-q_{1}\right) f_{1}(x) d x \\
& \quad-r_{0} \int_{0}^{q_{1} / q_{0}}\left(q_{1}-q_{0} x\right) f_{1}(x) d x .
\end{aligned}
$$

Proposition 4. Under the quantity discount contract, the supplier's expected profit function, $E\left(\pi_{1}^{Q D}\right)$, is concave in $q_{0}$, and the optimal production quantity of the raw material, $q_{0}^{Q D}$, satisfies the following equation:

$$
\begin{gathered}
\int_{0}^{q_{1} / q_{0}} x f_{1}(x) d x-\frac{\alpha p_{0}}{p_{0}+h_{0}+r_{0}} \int_{q^{*} / q_{0}}^{q_{1} / q_{0}} x f_{1}(x) d x \\
\quad=\frac{c_{0}+h_{0}}{p_{0}+h_{0}+r_{0}} .
\end{gathered}
$$


Proof. Since

$$
\begin{aligned}
\frac{d E\left[\pi_{1}^{\mathrm{QD}}\left(q_{0}\right)\right]}{d q_{0}}= & \left(p_{0}+h_{0}+r_{0}\right) \int_{0}^{q_{1} / q_{0}} x f_{1}(x) d x \\
& -\alpha p_{0} \int_{q^{*} / q_{0}}^{q_{1} / q_{0}} x f_{1}(x) d x-c_{0}-h_{0}, \\
\frac{d^{2} E\left[\pi_{1}^{\mathrm{QD}}\left(q_{0}\right)\right]}{d q_{0}^{2}}= & -\left(p_{0}+h_{0}+r_{0}-\alpha p_{0}\right) \frac{q_{1}^{2}}{q_{0}^{3}} f_{1}\left(\frac{q_{1}}{q_{0}}\right) \\
& -\alpha p_{0} \frac{q^{* 2}}{q_{0}^{3}} f_{1}\left(\frac{q^{*}}{q_{0}}\right)<0 .
\end{aligned}
$$

So $E\left(\pi_{1}^{\mathrm{QD}}\right)$ is concave in $q_{0}$, and setting $\left(\partial E\left(\pi_{1}^{\mathrm{QD}}\right)\right) / \partial q_{0}=0$, we have (15).

Under the quantity discount contract, the profit of the manufacturer is

$$
\begin{aligned}
\pi_{1}^{\mathrm{QD}}\left(q_{1}\right)= & p_{1} \min \left[D \cdot Z, \min \left(q_{1}, q_{0} \cdot X\right) \cdot Y\right] \\
& -p_{0} \min \left[q_{1}, q_{0} \cdot X\right] \\
& +\alpha p_{0} \max \left[\min \left(q_{1}, q_{0} X\right)-q^{*}, 0\right] \\
& -c_{1}\left[\min \left(q_{1}, q_{0} \cdot X\right)\right] \\
& -h_{1} \max \left[\min \left(q_{1}, q_{0} \cdot X\right) \cdot Y-D \cdot Z, 0\right] \\
& -r_{1} \max \left[D \cdot Z-\left(\min \left(q_{1}, q_{0} \cdot X\right) \cdot Y\right), 0\right]
\end{aligned}
$$

The first term is the sales revenue of the manufacturer, the second term is the ordering cost of the raw material at the price of $p_{0}$, the third term is the price discount based on the quantity discount contract, the fourth term is the production cost of the manufacturer, the fifth term is the inventory cost of the manufacturer, and the sixth term is the shortage cost of the manufacturer.

The manufacturer operates under the constraint restrictions of the supplier and it precedes the decision making of production and ordering by the standard of maximizing the profits:

$$
\begin{aligned}
\max _{q_{1}} E[ & \left.\pi_{2}^{\mathrm{QD}}\left(q_{1}\right)\right] \\
= & p_{1} \int_{0}^{+\infty} g(z) d z \\
\times & {\left[\int_{0}^{q_{1} / q_{0}} d x \int_{0}^{D z / q_{0} x} q_{0} x y f_{1}(x) f_{2}(y) d y\right.} \\
& +\int_{0}^{q_{1} / q_{0}} d x \int_{D z / q_{0} x}^{+\infty} D z f_{1}(x) f_{2}(y) d y \\
& \quad+\int_{q_{1} / q_{0}}^{+\infty} d x \int_{0}^{D z / q_{1}} q_{1} y f_{1}(x) f_{2}(y) d y
\end{aligned}
$$

$$
\begin{aligned}
& \left.+\int_{q_{1} / q_{0}}^{+\infty} d x \int_{D z / q_{1}}^{+\infty} D z f_{1}(x) f_{2}(y) d y\right] \\
& -\left(p_{0}+c_{1}\right)\left[\int_{0}^{q_{1} / q_{0}} q_{0} x f_{1}(x) d x+\int_{q_{1} / q_{0}}^{+\infty} q_{1} f_{1}(x) d x\right] \\
& +\alpha p_{0}\left[\int_{q^{*} / q_{0}}^{q_{1} / q_{0}}\left(q_{0} x-q^{*}\right) f_{1}(x) d x\right. \\
& \left.+\int_{q_{1} / q_{0}}^{+\infty}\left(q_{1}-q^{*}\right) f_{1}(x) d x\right] \\
& -h_{1} \int_{0}^{+\infty} g(z) d z \\
& \times\left[\int_{0}^{q_{1} / q_{0}} d x \int_{D z / q_{0} x}^{+\infty}\left(q_{0} x y-D z\right) f_{1}(x) f_{2}(y) d y\right. \\
& \left.+\int_{q_{1} / q_{0}}^{+\infty} d x \int_{D z / q_{1}}^{+\infty}\left(q_{1} y-D z\right) f_{1}(x) f_{2}(y) d y\right] \\
& -r_{1} \int_{0}^{+\infty} g(z) d z \\
& \times\left[\int_{0}^{q_{1} / q_{0}} d x \int_{0}^{D z / q_{0} x}\left(D z-q_{0} x y\right) f_{1}(x) f_{2}(y) d y\right. \\
& \left.+\int_{q_{1} / q_{0}}^{+\infty} d x \int_{0}^{D z / q_{1}}\left(D z-q_{1} y\right) f_{1}(x) f_{2}(y) d y\right] \\
& \text { s.t. } \quad \int_{0}^{q_{1} / q_{0}} x f_{1}(x) d x-\frac{\alpha p_{0}}{p_{0}+h_{0}+r_{0}} \int_{q^{*} / q_{0}}^{q_{1} / q_{0}} x f_{1}(x) d x \\
& =\frac{c_{0}+h_{0}}{p_{0}+h_{0}+r_{0}} \text {. }
\end{aligned}
$$

Setting $d E\left[\pi_{2}^{\mathrm{QD}}\left(q_{1}\right)\right] / d q_{1}=0$, we obtain the optimal order quantity, $q_{1}^{\mathrm{QD}}$, which satisfies the following equation:

$$
\begin{aligned}
& \left(p_{1}+h_{1}+r_{1}\right) \int_{0}^{+\infty} g(z) d z \\
& \times\left[\int_{0}^{q_{1} / q_{0}} d x \int_{0}^{D z / q_{0} x} q_{0}^{\prime} x y f_{1}(x) f_{2}(y) d y\right. \\
& \left.\quad+\int_{q_{1} / q_{0}}^{+\infty} d x \int_{0}^{D z / q_{1}} y f_{1}(x) f_{2}(y) d y\right] \\
& -\left(p_{0}+c_{1}+h_{1}-\alpha p_{0}\right) \\
& \times\left[\int_{0}^{q_{1} / q_{0}} q_{0}^{\prime} x f_{1}(x) d x+\int_{q_{1} / q_{0}}^{+\infty} f_{1}(x) d x\right] \\
& -\alpha p_{0} \int_{0}^{q^{*} / q_{0}} q_{0}^{\prime} x f_{1}(x) d x=0 .
\end{aligned}
$$

The $q_{0}$ is a function of $q_{1}$ from (15), and $q_{0}^{\prime}$ is $q_{0}$ 's derivative by $q_{1}$. 
TABLE 2: Numerical results for all models $(m=0.15, n=0.1, l=0.2)$.

\begin{tabular}{|c|c|c|c|c|c|c|c|c|}
\hline \multirow[t]{2}{*}{ Model } & \multicolumn{2}{|c|}{$\begin{array}{l}\text { Quantity discount } \\
\text { parameters }\end{array}$} & \multicolumn{3}{|c|}{$\begin{array}{l}\text { Decision making for } \\
\text { production and order }\end{array}$} & \multicolumn{3}{|c|}{ Expected profit } \\
\hline & $\alpha$ & $q^{*}$ & $q_{0}$ & $q_{1}$ & $q_{0} / q_{1}$ & $E\left(\pi_{1}\right)$ & $E\left(\pi_{2}\right)$ & $E\left(\pi_{0}\right)$ \\
\hline $\begin{array}{l}U: \text { independent and } \\
\text { noncoordinated decision }\end{array}$ & - & - & 425.6 & 419.7 & 1.014 & 7458.5 & 14683.0 & 22141.5 \\
\hline C: centralized decision & - & - & 435.1 & 435.1 & 1 & - & - & 22210.5 \\
\hline \multirow{4}{*}{$\begin{array}{l}\text { QD: quantity discount with } \\
\text { the supplier as a dominant } \\
\text { party }\end{array}$} & 0.1 & 385.3 & 441.5 & 438.7 & 1.006 & 7527.5 & 14683.0 & 22210.5 \\
\hline & 0.2 & 422.1 & 430.7 & 425.1 & 1.013 & 7527.5 & 14683.0 & 22210.5 \\
\hline & 0.3 & 423.1 & 430.7 & 425.1 & 1.013 & 7527.5 & 14683.0 & 22210.5 \\
\hline & 0.4 & 423.6 & 430.7 & 425.1 & 1.013 & 7527.5 & 14683.0 & 22210.5 \\
\hline \multirow{4}{*}{$\begin{array}{l}\text { QD: quantity discount with } \\
\text { the manufacturer as a } \\
\text { dominant party }\end{array}$} & 0.1 & 400.4 & 431.0 & 426.7 & 1.01 & 7458.5 & 14752.0 & 22210.5 \\
\hline & 0.2 & 403.3 & 439.7 & 438.1 & 1.004 & 7458.5 & 14752.0 & 22210.5 \\
\hline & 0.3 & 417.3 & 431.0 & 427.0 & 1.009 & 7458.5 & 14752.0 & 22210.5 \\
\hline & 0.4 & 419.7 & 439.2 & 437.9 & 1.003 & 7458.5 & 14752.0 & 22210.5 \\
\hline
\end{tabular}

\section{The Design of Quantity Discount Contracts}

The actual producing activities can be boiled down to the issue of the Stackelberg game problem. Quantity discount contracts, under both the supplier as the dominant side and the manufacturer as the dominant side, are to be discussed separately. The principle of designing the pact is as follows.

(1) In the Stackelberg game, the dominant side fulfills the quantity discount coordination of the supply chain, through the determination of the quantity discount qualification point and the price discount rate.

(2) Considering the rationality of the follower, the dominant side for the acceptance of the strategy by the follower should ensure that the interest of the follower should be no less than the interest gained under the noncoordinated pattern.

(3) Based on the fulfillment of the above conditions, the expected profit of the dominant side should be maximized.

6.1. The Quantity Discount Contract with the Supplier as the Dominant Side. Under the uncertainty of the two-echelon yields and demand, provided that the supplier holds the dominant position, with the manufacturer being the follower, the supplier is in the position to determine the parameter package of the quantity discount, including the quantity discount qualification point, $q^{*}$, and the price discount rate, $\alpha$, so as to realize the coordination in the supply chain. The model is as follows:

$$
\begin{array}{ll}
\max & E\left(\pi_{1}^{\mathrm{QD}}\right) \\
\text { s.t. } & \left\{\begin{array}{l}
\text { Equation }(19) \\
E\left(\pi_{2}^{\mathrm{QD}}\right) \geq E\left(\pi_{2}^{U}\right) .
\end{array}\right.
\end{array}
$$

For the first item, as the supplier holds the dominant position, the goal is to achieve the maximized profit of the supplier in the decision making. The second item represents the ordering strategy of the manufacturer; the third item guarantees the profits of the manufacturer should not be less than that under independent and noncoordinated decision making pattern.

6.2. The Quantity Discount Contract with the Manufacturer as the Dominant Party. Under the uncertainty of the twoechelon yields and demand in supply chains, given that the manufacturer is in the dominant position in quantity discount and coordination, with the supplier in a secondary position, the manufacturer determines the parameter package of quantity discount, including the quantity discount qualification point and the price discount rate, so as to realize coordination in supply chains. The model is shown as below:

$$
\begin{array}{ll}
\max & E\left(\pi_{2}^{\mathrm{QD}}\right) \\
\text { s.t. } & \left\{\begin{array}{l}
\text { Equation }(15) \\
E\left(\pi_{1}^{\mathrm{QD}}\right) \geq E\left(\pi_{1}^{U}\right) .
\end{array}\right.
\end{array}
$$

The first item shows that the goal to be achieved is to maximize the profit of the manufacturer in the decision making; the second item shows that the ordering strategy is provided by the supplier; the third item shows that the supplier's profit level should be kept no less than the level under the independent and noncoordinated decision-making pattern.

\section{Numerical Examples and Discussions}

The parameters of a certain supply chain are set as below: $c_{0}=20, h_{0}=5, r_{0}=15, c_{1}=10, h_{1}=7, r_{1}=30$, $p_{0}=40, p_{1}=95, D=400$. The output of the supplier and the output of the manufacturer, random variables for market demand of the finished products, are uniformly distributed over $[1-m, 1+m],[1-n, 1+n]$, and $[1-l, 1+l]$, respectively.

Tables 2-4 present the decision making for production and ordering and the expected profits under an independent 
TABLE 3: Numerical results for all models $(m=0.2, n=0.2, l=0.2)$.

\begin{tabular}{|c|c|c|c|c|c|c|c|c|}
\hline \multirow[t]{2}{*}{ Model } & \multicolumn{2}{|c|}{$\begin{array}{l}\text { Quantity discount } \\
\text { parameters }\end{array}$} & \multicolumn{3}{|c|}{$\begin{array}{l}\text { Decision making for } \\
\text { production and order }\end{array}$} & \multicolumn{3}{|c|}{ Expected profit } \\
\hline & $\alpha$ & $q^{*}$ & $q_{0}$ & $q_{1}$ & $q_{0} / q_{1}$ & $E\left(\pi_{1}\right)$ & $E\left(\pi_{2}\right)$ & $E\left(\pi_{0}\right)$ \\
\hline $\begin{array}{l}U: \text { independent and } \\
\text { noncoordinated decision }\end{array}$ & - & - & 434.5 & 429.3 & 1.012 & 7108.5 & 14100.7 & 21209.3 \\
\hline$C$ : centralized decision & - & - & 453.7 & 453.7 & 1 & - & - & 21654.2 \\
\hline \multirow{4}{*}{$\begin{array}{l}\text { QD: quantity discount with } \\
\text { the supplier as a dominant } \\
\text { party }\end{array}$} & 0.1 & 412.5 & 459.2 & 455.8 & 1.007 & 7553.5 & 14100.7 & 21654.2 \\
\hline & 0.2 & 433.0 & 459.0 & 455.8 & 1.007 & 7553.5 & 14100.7 & 21654.2 \\
\hline & 0.3 & 443.3 & 451.5 & 446.0 & 1.012 & 7553.5 & 14100.7 & 21654.2 \\
\hline & 0.4 & 444.0 & 451.5 & 446.0 & 1.012 & 7553.5 & 14100.7 & 21654.2 \\
\hline \multirow{4}{*}{$\begin{array}{l}\text { QD: quantity discount with } \\
\text { the manufacturer as a } \\
\text { dominant party }\end{array}$} & 0.1 & 351.7 & 453.4 & 453.4 & 1 & 7186.9 & 14467.3 & 21654.2 \\
\hline & 0.2 & 405.8 & 453.3 & 453.2 & 1 & 7275.9 & 14378.3 & 21654.2 \\
\hline & 0.3 & 422.2 & 453.2 & 453.1 & 1 & 7300.7 & 14353.5 & 21654.2 \\
\hline & 0.4 & 430.2 & 453.2 & 453.1 & 1 & 7312.3 & 14341.9 & 21654.2 \\
\hline
\end{tabular}

TABLE 4: Numerical results for all models $(m=0.15, n=0.1, l=0.3)$.

\begin{tabular}{|c|c|c|c|c|c|c|c|c|}
\hline \multirow[t]{2}{*}{ Model } & \multicolumn{2}{|c|}{$\begin{array}{l}\text { Quantity discount } \\
\text { parameters }\end{array}$} & \multicolumn{3}{|c|}{$\begin{array}{l}\text { Decision making for } \\
\text { production and order }\end{array}$} & \multicolumn{3}{|c|}{ Expected profit } \\
\hline & $\alpha$ & $q^{*}$ & $q_{0}$ & $q_{1}$ & $q_{0} / q_{1}$ & $E\left(\pi_{1}\right)$ & $E\left(\pi_{2}\right)$ & $E\left(\pi_{0}\right)$ \\
\hline $\begin{array}{l}U: \text { independent and } \\
\text { noncoordinated decision }\end{array}$ & - & - & 429.1 & 423.2 & 1.014 & 7519.6 & 12523.1 & 20042.7 \\
\hline C: centralized decision & - & - & 438.7 & 438.7 & 1 & - & - & 20112.3 \\
\hline \multirow{4}{*}{$\begin{array}{l}\text { QD: quantity discount with } \\
\text { the supplier as a dominant } \\
\text { party }\end{array}$} & 0.1 & 422.7 & 434.2 & 428.6 & 1.013 & 7589.2 & 12523.1 & 20112.3 \\
\hline & 0.2 & 425.6 & 434.2 & 428.6 & 1.013 & 7589.2 & 12523.1 & 20112.3 \\
\hline & 0.3 & 426.6 & 434.2 & 428.6 & 1.013 & 7589.2 & 12523.1 & 20112.3 \\
\hline & 0.4 & 427.1 & 434.2 & 428.6 & 1.013 & 7589.2 & 12523.1 & 20112.3 \\
\hline \multirow{4}{*}{$\begin{array}{l}\text { QD: quantity discount with } \\
\text { the manufacturer as a } \\
\text { dominant party }\end{array}$} & 0.1 & 403.6 & 434.6 & 430.5 & 1.01 & 7519.6 & 12592.7 & 20112.3 \\
\hline & 0.2 & 416.2 & 434.6 & 430.5 & 1.01 & 7519.6 & 12592.7 & 20112.3 \\
\hline & 0.3 & 420.7 & 434.6 & 430.5 & 1.01 & 7519.6 & 12592.7 & 20112.3 \\
\hline & 0.4 & 423.1 & 434.6 & 430.5 & 1.01 & 7519.6 & 12592.7 & 20112.3 \\
\hline
\end{tabular}

and noncoordinated decision-making pattern and the centralized decision making pattern, under the the uncertainty of the two-echelon yields and demand; they also, respectively, present quantity discount coordination decision making with the supplier as the dominant role solving by model (20) and the quantity discount coordination decision making with the manufacturer as the dominant role solving by model (21).

With Tables 2-4, the following conclusions can be drawn.

(1) Under an independent decision-making pattern, there exists the Nash equilibrium between the supplier and the manufacturer, and the profit under the Nash equilibrium is less than that gained under the centralized decision-making pattern; under the quantity discount pact, the manufacturer has increased the ordering quantity of the raw material; the ratios of the planned output of the supplier to the ordering quantity of the manufacturer have decreased.

(2) Under the quantity discount pact with the supplier in the dominant position, the supplier sets different combinations of the quantity discount qualification point and the price discount rate, under the situation where the profit of the manufacturer under the quantity discount coordination pact exceeds that under independent and noncoordinated decision-making pattern. In this sense, the profit of the supply chain based on quantity discount reaches the profit level of the chain under a centralized pattern. The supplier and the manufacturer can select a certain combination and set forth a quantity discount coordination pact.

(3) Under the quantity discount coordination with the manufacturer in the dominant position, the manufacturer sets different combinations as well. With the profit of the supply chain under the quantity discount coordination pact exceeding the profit under the independent and noncoordinated decision-making pattern, the chain profit based on quantity discount reaches the profit level gained in a centralized pattern. The supplier and the manufacturer can select a certain 
combination and set forth a quantity discount coordination pact.

(4) With a comparison of Tables 2, 3, and 4, it can be found that the larger the uncertainty of two-echelon yields and demand, the larger the contribution of the quantity discount coordination pact to the profit of the supply chains. With $m=0.15, n=0.1$, and $l=$ 0.2 , the quantity discount coordination pact helps increase the total profit by $0.3 \%$. With $m=0.15$, $n=0.1$, and $l=0.3$, the quantity discount coordination pact helps increase the total profit by $0.4 \%$. With $m=0.2, n=0.2$, and $l=0.2$, the quantity discount coordination pact helps increase the total profit by $2.1 \%$. This shows that the quantity discount coordination contract can effectively reduce the negative effect by the uncertainty of two-echelon yields and demand upon the efficiency and benefit of the supply chains.

(5) We also find out that under most scenarios, the supply chain benefits from the yields and demand risks reduction and generates a higher profit. Contrasting Tables 2 and 3, we find out that sometimes in the quantity discount contract the supplier's profit can increase as yields' randomness increases. And contrasting Tables 2 and 4, we find out that, in the uncoordinated case and quantity discount contract, the supplier's profit can increase as demand randomness increases.

\section{Conclusions}

This paper explores the quantity discount coordination models in the fashion supply chain with uncertain yields and random demand. The planned production outputs of the supplier and the ordering quantity of the manufacturer have been set as the decision-making parameters. The independent and noncoordinated and centralized decision-making patterns have been established under the uncertainty of twoechelon yields and demand. Through the analysis, it has been found that the profit of supply chains under independent and noncoordinated decision-making pattern is less than that under the centralized pattern, which proves the necessity of the coordination of supply chains. Based on this, two parameters-quantity discount qualification point and price discount ratio-have been introduced and quantity discount coordination models have been established. The quantity discount coordination pacts with both the supplier and the manufacturer in the dominant position have been set forth.

The result reveals that the quantity discount coordination pact proposed by this paper can promote the manufacturer's ordering quantity of the raw material, which contributes to the result that the profit of the supply chain based on quantity discount reaches the profit level of the supply chain under the centralized decision-making pattern. The larger the uncertainty of two-echelon yields and demand, the larger contribution of the pact to the benefit of the supply chain will be. The quantity discount coordination pact under the uncertainty of two-echelon yields and demand can reduce the negative influence brought by the uncertainty and therefore can contribute to the purpose of the coordination of the supply chain.

\section{Acknowledgments}

The authors would like to thank the referees for their constructive comments and suggestions that have greatly improved the quality of the paper. The research was supported by the National Natural Science Foundation of China (Grant no. 71201164).

\section{References}

[1] D. J. Thomas and P. M. Griffin, "Coordinated supply chain management," European Journal of Operational Research, vol. 94, no. 1, pp. 1-15, 1996.

[2] N. Agrawal, S. A. Smith, and A. A. Tsay, "Multi-vendor sourcing in a retail supply chain," Production and Operations Management, vol. 11, no. 2, pp. 157-181, 2002.

[3] C. Chiang and W. C. Benton, "Sole sourcing versus dual sourcing under stochastic demands and lead times," Naval Research Logistics, vol. 41, no. 5, pp. 609-624, 1994.

[4] J. D. Hong and J. C. Hayya, "Just-in-time purchasing: single or multiple sourcing?" International Journal of Production Economics, vol. 27, no. 2, pp. 175-181, 1992.

[5] M. Treleven and S. B. Schweikhart, "A risk/benefit analysis of sourcing strategies: single vs. multiple sourcing," Journal of Operations Management, vol. 7, no. 3-4, pp. 93-114, 1988.

[6] G. P. Cachon and P. H. Zipkin, "Competitive and cooperative inventory policies in a two-stage supply chain," Management Science, vol. 45, no. 7, pp. 936-953, 1999.

[7] M. Leng and M. Parlar, "Game theoretic applications in supply chain management: a review," INFOR, vol. 43, no. 3, pp. 187-220, 2005.

[8] M. Moses and S. Seshadri, "Policy mechanisms for supply chain coordination," IIE Transactions, vol. 32, no. 3, pp. 245-262, 2000.

[9] H. J. Peng and M. H. Zhou, "Production and ordering decision in supply chain with uncertainty in two-echelon yields and demand," Journal of Systems Engineering, vol. 25, no. 5, pp. 622628, 2010 (Chinese).

[10] C. T. Chang, "An acquisition policy for a single item multisupplier system with real-world constraints," Applied Mathematical Modelling, vol. 30, no. 1, pp. 1-9, 2006.

[11] C. T. Chang, C. L. Chin, and M. F. Lin, "On the single item multi-supplier system with variable lead-time, price-quantity discount, and resource constraints," Applied Mathematics and Computation, vol. 182, no. 1, pp. 89-97, 2006.

[12] J. Li and L. Liu, "Supply chain coordination with quantity discount policy," International Journal of Production Economics, vol. 101, no. 1, pp. 89-98, 2006.

[13] C. L. Munson and M. J. Rosenblatt, "Theories and realities of quantity discounts: an exploratory study," Production and Operations Management, vol. 7, no. 4, pp. 352-369, 1998.

[14] C. L. Munson and J. Hu, "Incorporating quantity discounts and their inventory impacts into the centralized purchasing decision," European Journal of Operational Research, vol. 201, no. 2, pp. 581-592, 2010.

[15] H. Y. Kang and A. H. I. Lee, "Inventory replenishment model using fuzzy multiple objective programming: a case study 
of a high-tech company in Taiwan," Applied Soft Computing Journal, vol. 10, no. 4, pp. 1108-1118, 2010.

[16] A. Mendoza and J. A. Ventura, "Incorporating quantity discounts to the EOQ model with transportation costs," International Journal of Production Economics, vol. 113, no. 2, pp. 754$765,2008$.

[17] J. Moussourakis and C. Haksever, "A practical model for ordering in multi-product multi-constraint inventory systems with all-units quantity discounts," International Journal of Information and Management Sciences, vol. 19, no. 2, pp. 263283, 2008.

[18] P. A. Rubin and W. C. Benton, "A generalized framework for quantity discount pricing schedules," Decision Sciences, vol. 34, no. 1, pp. 173-188, 2003.

[19] G. Zhang and L. Ma, "Optimal acquisition policy with quantity discounts and uncertain demands," International Journal of Production Research, vol. 47, no. 9, pp. 2409-2425, 2009.

[20] G. Zhang, "The multi-product newsboy problem with supplier quantity discounts and a budget constraint," European Journal of Operational Research, vol. 206, no. 2, pp. 350-360, 2010.

[21] A. H. I. Lee and H. Y. Kang, "A mixed 0-1 integer programming for inventory model: a case study of TFT-LCD manufacturing company in Taiwan," Kybernetes, vol. 37, no. 1, pp. 66-82, 2008.

[22] J. Shi and G. Zhang, "Multi-product budget-constrained acquisition and pricing with uncertain demand and supplier quantity discounts," International Journal of Production Economics, vol. 128, no. 1, pp. 322-331, 2010.

[23] A. A. Taleizadeh, S. T. A. Niaki, and R. Nikousokhan, "Constraint multiproduct joint-replenishment inventory control problem using uncertain programming," Applied Soft Computing, vol. 11, pp. 5143-5154, 2011.

[24] J. Rezaei and M. Davoodi, "A deterministic, multi-item inventory model with supplier selection and imperfect quality," Applied Mathematical Modelling, vol. 32, no. 10, pp. 2106-2116, 2008.

[25] Y. Duan, J. Luo, and J. Huo, "Buyer-vendor inventory coordination with quantity discount incentive for fixed lifetime product," International Journal of Production Economics, vol. 128, no. 1, pp. 351-357, 2010.

[26] S. P. Chen and Y. H. Ho, "Analysis of the newsboy problem with fuzzy demands and incremental discounts," International Journal of Production Economics, vol. 129, no. 1, pp. 169-177, 2011.

[27] Y. J. Lin and C. H. Ho, "Integrated inventory model with quantity discount and price-sensitive demand," Top, vol. 19, no. 1, pp. 177-188, 2011.

[28] S. Krichen, A. Laabidi, and F. B. Abdelaziz, "Single supplier multiple cooperative retailers inventory model with quantity discount and permissible delay in payments," Computers and Industrial Engineering, vol. 60, no. 1, pp. 164-172, 2011.

[29] J. Shi, G. Zhang, and J. Sha, "Jointly pricing and ordering for a multi-product multi-constraint newsvendor problem with supplier quantity discounts," Applied Mathematical Modelling, vol. 35, no. 6, pp. 3001-3011, 2011.

[30] H. Shin and W. C. Benton, "A quantity discount approach to supply chain coordination," European Journal of Operational Research, vol. 180, no. 2, pp. 601-616, 2007.

[31] H. Gurnani and Y. Gerchak, "Coordination in decentralized assembly systems with uncertain component yields," European Journal of Operational Research, vol. 176, no. 3, pp. 1559-1576, 2007.
[32] Y. He and J. Zhang, "Random yield risk sharing in a two-level supply chain," International Journal of Production Economics, vol. 112, no. 2, pp. 769-781, 2008.

[33] Y. He and J. Zhang, "Random yield supply chain with a yield dependent secondary market," European Journal of Operational Research, vol. 206, no. 1, pp. 221-230, 2010.

[34] C. C. Hsieh and C. H. Wu, "Capacity allocation, ordering, and pricing decisions in a supply chain with demand and supply uncertainties," European Journal of Operational Research, vol. 184, no. 2, pp. 667-684, 2008.

[35] C. C. Hsieh and C. H. Wu, "Coordinated decisions for substitutable products in a common retailer supply chain," European Journal of Operational Research, vol. 196, no. 1, pp. 273-288, 2009.

[36] A. Hsu and Y. Bassok, "Random yield and random demand in a production system with downward substitution," Operations Research, vol. 47, no. 2, pp. 277-290, 1999.

[37] P. Kelle, S. Transchel, and S. Minner, "Buyer-supplier cooperation and negotiation support with random yield consideration," International Journal of Production Economics, vol. 118, no. 1, pp. 152-159, 2009.

[38] B. Keren, "The single-period inventory problem: extension to random yield from the perspective of the supply chain," Omega, vol. 37, no. 4, pp. 801-810, 2009.

[39] P. Kouvelis and J. M. Milner, "Supply chain capacity and outsourcing decisions: the dynamic interplay of demand and supply uncertainty," IIE Transactions, vol. 34, no. 8, pp. 717-728, 2002.

[40] X. Yan, M. Zhang, and K. Liu, "A note on coordination in decentralized assembly systems with uncertain component yields," European Journal of Operational Research, vol. 205, no. 2, pp. 469-478, 2010.

[41] B. Tomlin, "On the value of mitigation and contingency strategies for managing supply chain disruption risks," Management Science, vol. 52, no. 5, pp. 639-657, 2006.

[42] K. Zimmer, "Supply chain coordination with uncertain just-intime delivery," International Journal of Production Economics, vol. 77, no. 1, pp. 1-15, 2002. 


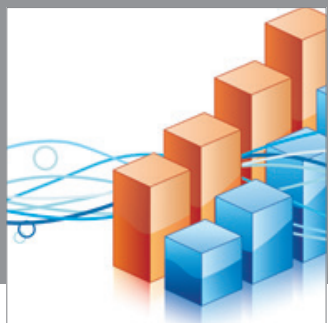

Advances in

Operations Research

mansans

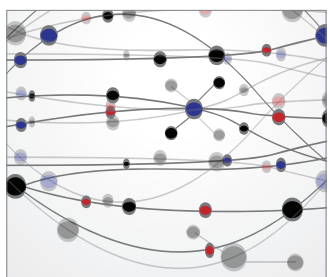

The Scientific World Journal
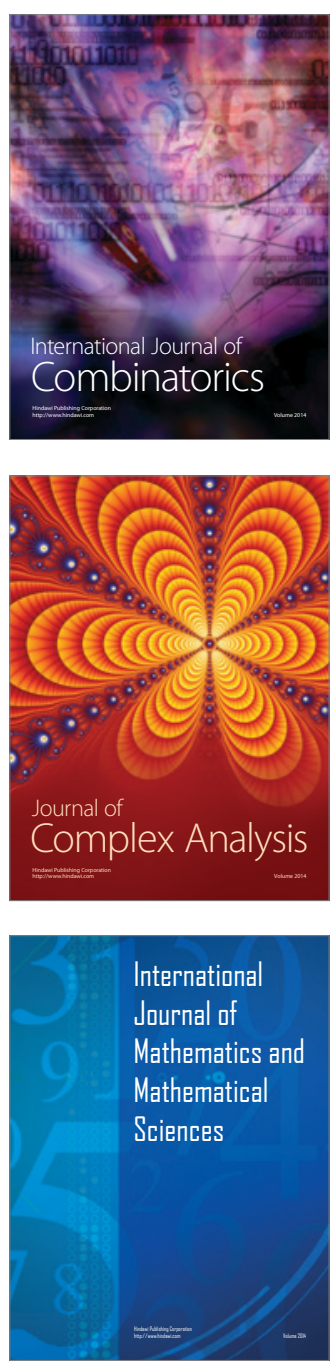
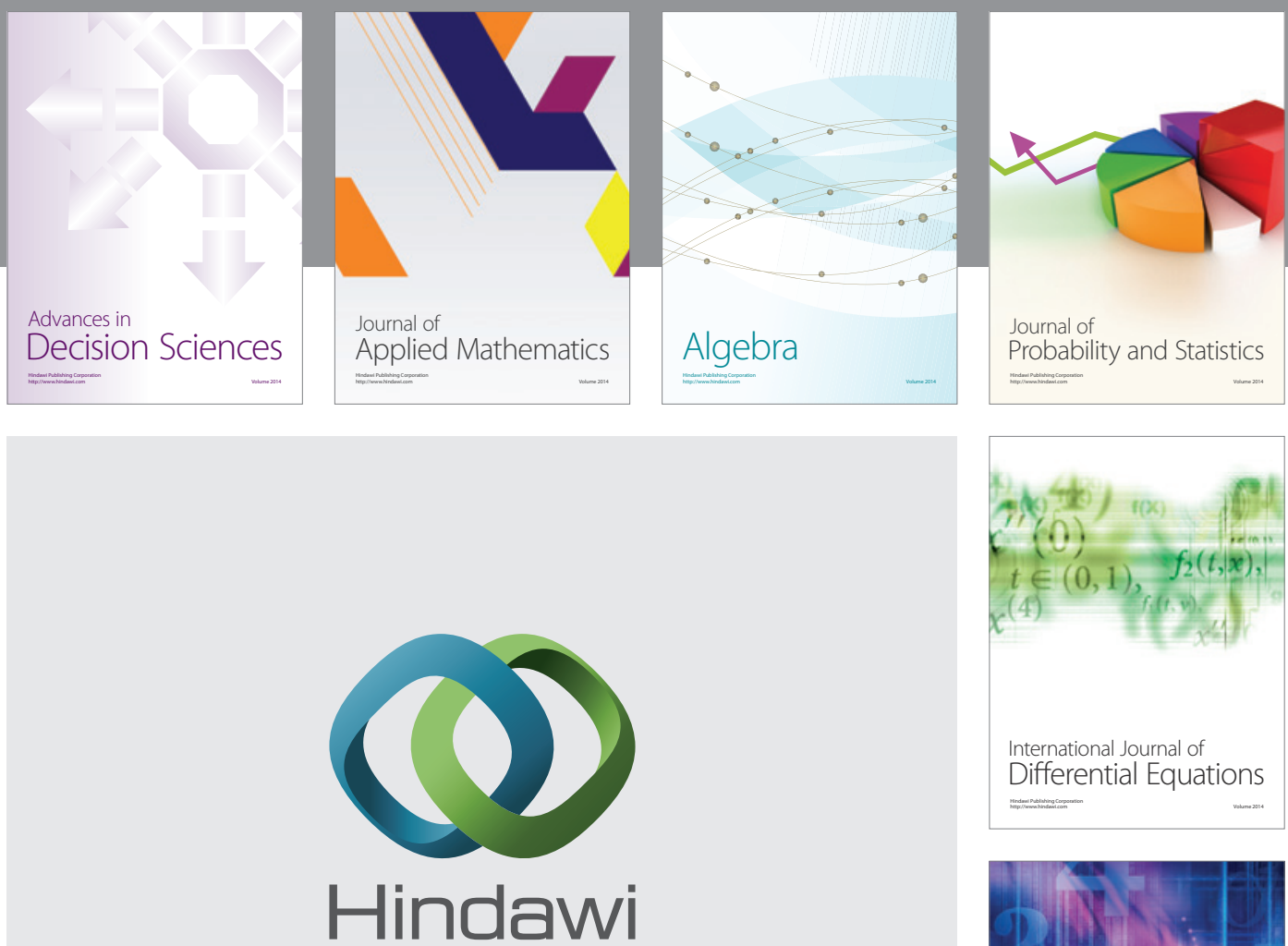

Submit your manuscripts at http://www.hindawi.com
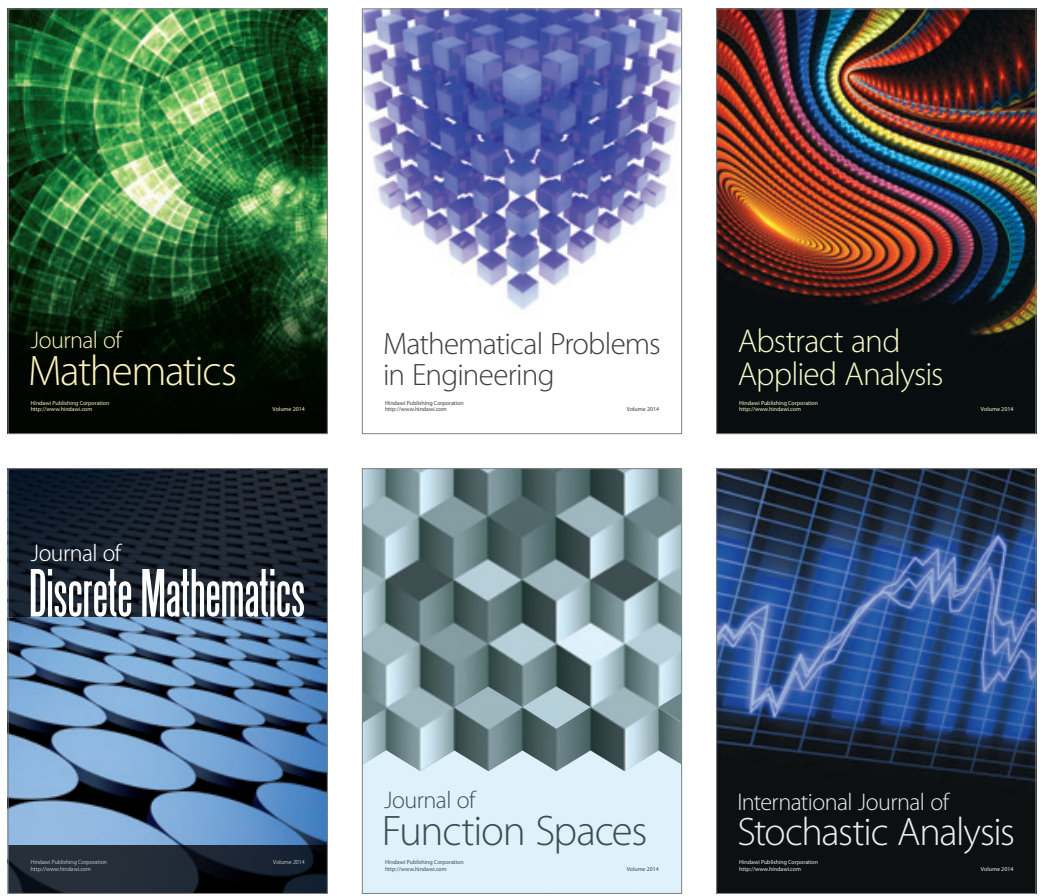

Journal of

Function Spaces

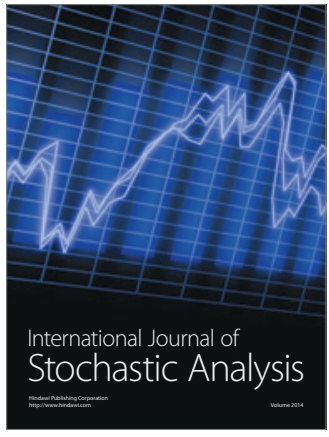

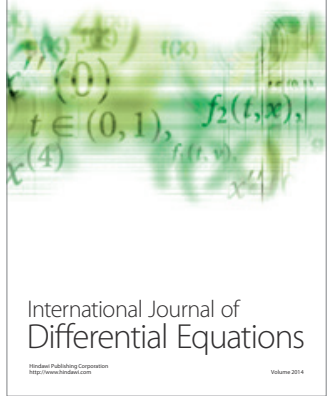
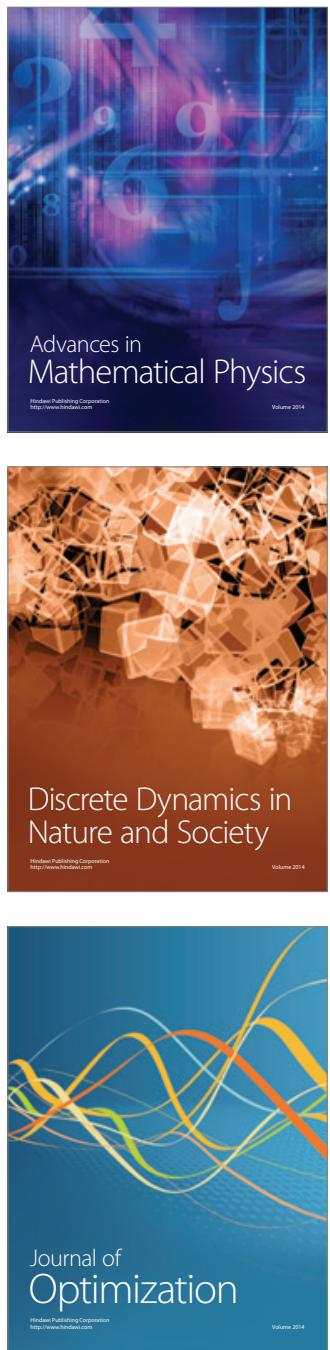